Байкова Оксана Викторовна

канд. экон. наук, ФГБОУ ВО «Государственный университет управления», г. Москва

e-mail: o-baykova@yandex.ru

Кулаков Дмитрий Анатольевич аспирант, ФГБОУ ВО «Государственный университет управления», г. Москва

e-mail: running_stream@mail.ru

\section{Baikova Oksana}

Candidate of Economic Sciences, State University of Management, Moscow

e-mail: o-baykova@yandex.ru

Kulakov Dmitrii

Postgraduate Student, State University of Management, Moscow

e-mail: running_stream@mail.ru

\section{АЛГОРИТМ ВЗАИМОДЕЙСТВИЯ ПРЕДПРИЯТИЙ ТОПЛИВНО-ЭНЕРГЕТИЧЕСКОГО КОМПЛЕКСА ПРИ РЕАЛИЗАЦИИ СДЕЛОК С ИСПОЛЬЗОВАНИЕМ АЛЬТЕРНАТИВНЫХ ПЛАТЕЖНЫХ СРЕДСТВ}

Аннотация. Предложена структура алгоритма построения системь платежного взаимодействия предприятий топливно-энергетического комплекса. Выделена необходимость при проведении оценки стоимости активов предприятий топливно-энергетического комплекса включения в ее состав таких нематериальных компонентов, как доверие, деловая репутация, прозрачность экономических отношений. Обозначена возможность более иирокого применения механизмов безденежной торговли в условиях экономики «недоверия» и политико-экономического кризиса. Выявлены особенности сотрудничества между предприятиями топливно-энергетического комплекса в условиях санкиионного давления, переходящего в торговую войну. Найдены возможности активизации и развития ресурсной торговли как одного из основных факторов повыщения защчщценности топливно-энергетического комплекса и всей российской экономики в ичелом.

Ключевые слова: доверие, взаимодействие, топливно-энергетический комплекс, бартер, безденежная торговля, прозрачность, санкции.

\section{THE ALGORITHM OF INTERACTION OF THE ENTERPRISES OF FUEL AND ENERGY COMPLEX IN IMPLEMENTATION WITH THE USE OF ALTERNATIVE MEANS OF PAYMENT}

\begin{abstract}
The structure of the algorithm for building a system of payment interaction of enterprises of the fuel and energy complex has been offered. The necessity to include such intangible components as trust, business reputation, transparency of economic relations in the assessment of the value of assets of the fuel and energy complex enterprises has been highlighted. The possibility of wider application of mechanisms of non-monetary trade in the conditions of economy of "distrust" and political and economic crisis has been designated. The peculiartities of cooperation between the enterprises of the fuel and energy complex in the conditions of sanctions pressure, turning into a trade war have been revealed. The possibilities of activation and development of resource trade as one of the main factors of increasing the security of the fuel and energy complex and the Russian economy as a whole have been discovered.
\end{abstract}

Keywords: trust, interaction, fuel and energy complex, barter, cashless trade, transparency, sanctions.

В эпоху всемирной глобализации некоторые страны (США, страны Евросоюза) считают себя способными создавать мировую гегемонию прежде всего экономико-политическими средствами. Путем санкционного давления они неоднократно угрожают многим экономикам (в том числе экономикам России, Китая, Индии) изоляцией, банкротством, что вносит в экономические механизмы настроения враждебности и недоверия [6]. Страны Европы и США, прикрываясь альтруистическим отношением к современному мироустройству, прежде всего введенными санкциями, на фоне глобального экономико-политического кризиса пытаются приобрести изначально конкурентные преимущества. Это ярко видно при воздействии на энергетический сектор экономики Российской Федерации.

Усиление санкций США с возможным ограничением проведения долларовых расчетов и сильная волатильность национальных валют вынуждают отдельные предприятия, секторы и экономики некоторых стран

( С Байкова О.В., Кулаков Д.А., 2019. Статья доступна по лицензии Creative Commons «Attribution» («Атрибуция») 4.0. всемирная (http://creativecommons.org/licenses/by/4.0/).

The Author(s), 2018. This is an open access article under the CC BY 4.0 license (http://creativecommons.org/licenses/by/4.0/). 
активнее, чем раньше применять сделки с использованием альтернативными средств платежей [2]. При заключении подобных сделок возникают ключевые вопросы ценности и оценки стоимости обмениваемых товаров. В настоящей статье в качестве товара рассмотрены продукты производства топливно-энергетического комплекса (далее - ТЭК), имеющие свои особенности.

При заключении подобных сделок в процессе реализации алгоритма взаимодействия между предприятиями человеческая природа играет очень важную роль. Особенно это касается реализации сделок и соглашений с использованием альтернативных средств платежей в ТЭК. Межличностные отношения на уровне людей, принимающих решения, составляют основную часть процесса коммуникации между предприятиями, другими словами это определение направлений и хода развития сотрудничества от предприятия к предприятию, от команды к команде (управленцев), от человека к человеку.

В экономико-социальном поведении предприятий ТЭК существуют типичные формы экономических отношений, которые связаны с достижением конкретных целей. Модель построения отношений между предприятиями можно представить в виде алгоритма, состоящего из повторяющихся процессов с прогнозируемыми сценариями развития. Алгоритм взаимодействия между предприятиями ТЭК при подготовке и реализации бартерных сделок можно представить следующим образом.

Эman 1. Формирование потребности в приобретении/реализации продукции, сырья (активов, технологий) или услуг.

Этап 2. Анализ рынка:

- уточнение характеристик имеющегося/необходимого товара и его количества;

- сбор информации о предложениях (продавцов, конкурирующих поставщиков о необходимом нам или имеющемся у нас товаре и аналогах);

- поиск и изучение информации о свободных экономических агентах, имеющих интересующее предложение или находящихся в числе потенциальных потребителей (изучение деловой репутации потенциальных контрагентов).

Эman 3. Формирование прогнозных ожиданий:

- формирование ожиданий как своих, так и потенциального контрагента;

- создание коммерческого предложения о возможном сотрудничестве.

Этап 4. Коммуникация:

- первичная коммуникация (начало прямого непосредственного контакта между должностными лицами предприятий - как правило телефонный звонок).

- при необходимости корректировка коммерческого предложения в соответствии с данными о потенциальном контрагенте.

- запрос/отправка коммерческого предложения. В случае отрицательного ответа или его отсутствия ыполняется поиск нового свободного агента с потенциальной возможностью для сотрудничества. При положительном ответе на коммерческое предложение о продолжении взаимодействия осуществляется корректировка ожиданий;

- если в предыдущем действии получен положительный ответ о возможности продолжения взаимодействия, как правило следует контакт первичного менеджерского звена (уровень менеджера продаж/закупок);

- подготовка к проведению переговоров лиц, принимающих решение (за решением компаний и даже стран все равно стоят люди);

- при положительном исходе переговоров, подтверждении актуальности и принятии дальнейшего решения о продолжении взаимодействия задействуются механизмы контрактно-договорной системы.

Этап 5. Сотрудничество:

- переход к более глубокой стадии взаимодействия - сотрудничеству в рамках контрактно-договорной системы (подготовка предварительного контракта).

- реализация сделки.

Эman 6. «Прыжок веры».

После того, как стоимость (как основное условие) обмениваемых товаров согласована и учтены логистические риски и потери наступает время так называемого «прыжка веры», особенно если перемещение обмениваемых товаров происходит неодновременно. 
Этаn 7. Контроль проведения поставок.

Ведение технико-операционного контроля соблюдения условий контракта, как логистических процессов, так и качества получаемого товара.

Эman 8. Сравнение каждым контрагентом своих прогнозных ожиданий с реальностью. На данном этапе происходит процесс анализа удовлетворенности организации (в частности лиц, принимающих решения) результатом сделки.

Эman 9. Решение. В зависимости от результата оценки предыдущего пункта принимается решение о продолжении, приостановке или прекращении сотрудничества.

Эman 10. Отражение сделки в бухгалтерской отчетности.

Этап 11. Налогообложение.

Если реализация данных договоренностей подпадает под контроль системы налогообложения, то наступает реализация обязанностей предприятия как налогоплательщика.

В рамках этапа сотрудничества особо стоит выделить последовательность реализации бартерных сделок в ТЭК.

1. Подготовка условий контракта, включающих ценностно-стоимостные характеристики товара контрагентов.

2. Расчет стоимости обмениваемых товаров, который проводит каждый из контрагентов, исходя из своей системы ценностей (для предприятий, осуществляющих сотрудничество внутри страны, она общая).

3. Для проведения более взвешенной оценки стоимости необходимо учесть ценность таких нематериальных активов, как деловая репутация контрагента (предприятия в целом и ключевых управленцев должностных лиц, принимающих решения). Для этого вполне достаточно получить достоверную информацию об истории компании, топ-менеджменте и затем методом математической статистики станет возможно произвести анализ временных рядов. Таким образом, можно получить анализ динамики положительно заключенных сделок данной компанией без каких-либо отрицательных последствий для их контрагентов, что при заключении больших товарообменных сделок очень важно.

4. После оценки деловой репутации необходимо сформировать уровень доверия к своей компании для включения его в равную и справедливую оценку стоимости своих активов (необходимо «понравиться» контрагенту, убедить его в своей благонадежности и на этот коэффициент проиндексировать цену товара).

5. Если подготовка контракта осуществляется с вновь организованной, подконтрольной или зависимой от определенного политического давления организацией, то расчет в п. 3 необходимо проводить в отношении лиц, принимающих решения, где за динамические данные принимают успешно реализованные и нереализованные ими проекты.

6. После сравнения оценок стоимости с позиций всех контрагентов, возникает прямая зависимость ценности получаемого и обмениваемого товара. Оценка ценности, выполняемая в международной валюте, например в долларах США, теряет свою сбалансированность и объективность. Оценка в альтернативных средствах платежа, например в баррелях нефти, тоже подвержена колебаниям вследствие изменений стоимости на мировых рынках. В свете сказанного выше главным становится фактор ценности получаемого при безденежных расчетах товара, т. е. традиционная оценка стоимости актива в долларовом эквиваленте или в любой другой валюте должна быть усреднена за счет среднего (балансирующего показателя), которым по принципам равноправия всех стран может стать некий новый международный регулятор, возможно основанный на индексе счастья для стран контрагентов. Ведь и в ХХ веке, помимо политических факторов, существуют факторы гуманитарного баланса, сдерживающие многие страны от бездонной ямы бедности [4].

7. Оценка ликвидности каждого из видов товаров, участвующего в сделке.

8. При необходимости уплата таможенного обеспечения.

Формирование деловой репутации и «экономики доверия»- неотъемлемые составляющие цены, ценности и стоимости продуктов производства предприятий ТЭК. Оценку стоимости активов предприятий ТЭК при обмене обычно проводят в международной валюте, на сегодняшний день в долларах США, поскольку эта валюта традиционно ориентирована на международную ценность. 
Можно выделить 4 вида факторов, недооцениваемых в настоящее время, которые необходимо учитывать при формировании цены на продукты производства предприятий ТЭК при подготовке и реализации сделок с альтернативными средствами платежей [5].

1. Общественно-моральные ценности стратегического партнерства. «Стратегическое партнерство» предприятий, в рамках топливно-энергетического комплекса - процесс углубленного взаимодействия в рамках экономико-политических отношений. Основными средствами измерения данного показателя служат эффективность и продолжительность сотрудничества между контрагентами, являющимися стратегическими партнерами. Ценности данной группы факторов можно отнести к неявным нематериальным активам, которые при некоторых условиях ведут к одномоментным финансовым потерям.

2. Стоимость ответственности контрагентов. Оценка ответственности при заключении сделок должна содержать оценку текущих и будущих финансовых потерь (таких, как упущенная выгода всех участников сделки) и оценку не финансовых потерь (таких, как репутационные издержки).

3. Стоимость отношений сотрудничества. Стоимость отношений сотрудничества измеряют через расчет рисков неблагоприятного сценария реализации сделки или полного отказа от нее.

4. Ценности долгосрочного сотрудничества. Основой данного вида ценностей является время, которое можно взять в качестве главнго критерия для оценки продолжительности сотрудничества.

В настоящее время оценка стоимости продуктов производства предприятий ТЭК опирается на международные биржи, формирующие текущую стоимость нефти.

Первичная функция фондового рынка заключается в том, чтобы выступать в качестве посредника между продавцами и покупателями и гармонизировать их предпочтения посредством его работы [3].

В современном мире нефть прочно заняла 2-е место по ликвидности после золота. Показатель стоимости нефти на международных сырьевых биржах стал своеобразным локомотивом, основой для формирования цен на самые разнообразные, совершенно независимые или связанные с нефтью товары. Особенно хорошо это видно, если посмотреть на ценообразование других углеводородов (например, газа). С учетом того, что достаточно много расчетов в настоящий момент выполняется с применением альтернативных средств платежа, краеугольным камнем ценообразования является зависимость оценки стоимость нефти «в моменте» от стоимости долларов США, так как цену при подготовке подобных соглашений приходится фиксировать. При подготовке сделки, предусматривающей товарообмен, оценка стоимости товаров из-за волатильности индекса стоимости баррелях нефти получает погрешность на величину изменений как стоимости самого товара, так и валюты как величины измерений, используемой для изначальной оценки стоимости обмениваемых товаров относительно стоимости долларов США. Таким образом, становится понятна цель создания нового международного платежного средства, ценность которого более очевидна, чем ценность долларов США как международной валюты с абсолютной ликвидностью [1].

Нефть приобрела такие позиции лишь благодаря тому, что она является сырьем прежде всего для энерго-топливных ресурсов глобальной международной логистической системы (топливо для системы глобальных поставок). На сегодняшний день, биржевая стоимость любого вида энергии или углеводорода, к сожалению, не содержит в своей структуре такую группу показателей, как:

- уровень доверия;

- показатель деловой репутации;

- прозрачность сделки.

Каждый из таких показателей в цифровом выражении - прибавочный процент к существующим оценкам стоимости продуктов предприятий ТЭК, производимой контрагентами и являющимися основными потребителями подобного сырья и энергоресурсов.

Другие функции фондового рынка включают перераспределение ресурсов между различными корпорациями и секторами и обеспечение ликвидности для внутреннего роста кредитов и экспансии.

В настоящий момент прослеживается присутствие в сделках не только недооценки, но и переоценки при долларовых стоимостных показателях по отношению к более слабым национальным валютам других стран. Отсюда следует необходимость совершенствования методов оценки стоимости активов предприятий ТЭК для качественного снижения экономических потерь, особенно при подготовке и реализации сделок с альтернативными средствами платежа и создания политико-экономических условий перехода от «экономики знаний» к «экономике доверия». 
Проблема тотального недоверия, даже на уровне отношений между странами, сегодня активно обсуждается. Заместитель руководителя Департамента по вопросам нераспространения и контроля над вооружениями МИД России Андрей Белоусов 27.10.2018 г. заявил, что Россия готовится к оборонительной войне с США. Об этом он рассказал на заседании комитета Генассамблеи ООН [7]. В таких условиях создание среды безденежных экономических отношений между предприятиями становится стратегической задачей государства. Необходимо выделить следующие выгоды применения безденежного товарообмена с участием предприятий ТЭК.

1. При заключении товарообменных сделок, гораздо более эффективно учитывается геополитическое местонахождение обмениваемых товаров. (Газ в обмен на электричество один из ярких примеров такого сотрудничества в рамках поставок газа с ближайшего месторождения).

2. Появляется возможность создания более благоприятных условий для внешнеторговых поставщиков, особенно союзников в возможном военном конфликте (одним из примеров часть контрактов на создание АЭС в Индии).

3. Укрепляются экономические связи на территории союзного государства России и Белоруссии.

4. Прорабатывается возможность дедолларизации экономических отношений между предприятиями при принятии за эквивалент альтернативную доллару ценность, например стоимость 1 барреля нефти в национальной валюте страны потребителя.

При ухудшении международной обстановки будут трансформированы и экономические отношения. Но исходя из реальности, можно уверенно сделать вывод, что экономика России готова к любому неблагоприятному сценарию, и безденежная торговля занимает не последнее место в числе экономико-защитных мер.

\section{Библиографический список}

1. Постановление Правительства РФ от 22.11.2012 № 1207 «Об осуществлении контроля за внешнеторговыми бартерными сделками и их учета». - Режим доступа: http://base.garant.ru/70265746 (дата обращения: 10.01.2019).

2. Афанасьев, В. Я. и др. Нефтегазовый комплекс: производство, экономика, управление. Учебник для вузов / В. Я. Афанасьев, О. В. Байкова, О. И. Большакова и др.; под ред. Ю. Н. Линника, В. Я. Афанасьева. - Издание 2-е, дополненное и перераб. - М.: Экономика, 2017. - 780 с.

3. Байкова, О. В., Кулаков Д. А. Доверие в системе взаимодействия участников рынка при проведении расчетов с использованием альтернативных платежных средств в системе топливно- энергетического комплекса // Вестник университета. - 2017. - № 7-8. - С. 74-79.

4. Вишняков, Я. Д. и др. Основы противодействия терроризму: учеб. пособие для студ. высш. учеб. заведений / Вишняков Я. Д., Г. А. Бондаренко, С. Г. Васин, Е. В. Грацианский; под ред. Я. Д. Вишнякова. - М.: Издательский центр «Академия», 2006. $-240 \mathrm{c}$.

5. Новоселов, А. Л. и др. Экономика, организация и управление в области недропользования. Учебник и практикум / А. Л. Новоселов, О. Е. Медведева, И. Ю. Новоселова. Москва, 2017. - 625 с.

6. Яковлев, А. Ю. Терроризм в Индии: особенности эволюции, институты и технологии противодействия: дис. д-р. полит. наук: 23.00.02. - М., 2016. 327 с.

7. Официально Россия подтвердила, что готовится к войне с США // https://bb.lv/statja/v-mire/2018/10/27/oficialno-rossiya-podtverdila-chto-gotovitsya-k-voyne-s-ssha (дата обращения: 10.01.2019).

\section{References}

1. Postanovlenie Pravitel'stva RF ot 22.11.2012 № 1 207. «Ob osushchestvlenii kontrolya za vneshnetorgovymi barternymi sdelkami i ikh ucheta» [Resolution of the Government of the Russian Federation of 22.11.2012 № 1207. «On the implementation of control over foreign trade barter transactions and their accounting»]. Available at: http://base.garant.ru/70265746 (accessed 10.01.2018).

2. Afanas'ev V. Ya., Baikova O. V., Bolshakov O. I., et al. Neftegazovyi kompleks: proizvodstvo, ekonomika, upravlenie. Uchebnik dlya vuzov [Oil and gas complex: production, economy, management. Textbook for universities]. Ed. Linnik Yu. N., Afanas'ev V. Ya.; 2nd edition, supplemented and revised. Moscow, Ekonomika, 2017. 780 p.

3. Baikova O.V., Kulakov D.A. Doverie v sisteme vzaimodeistviya uchastnikov rynka pri provedenii raschetov s ispol'zovaniem al'ternativnykh platezhnykh sredstv v sisteme toplivno- energeticheskogo kompleksa [Confidence in the system of interaction 
of market participants when making calculations using alternative means of payment in the system of the fuel and energy complex]. Vestnik universiteta, 2017, I. 7-8, pp. 74-79.

4. Vishnyakov Ya. D., Bondarenko G. A., Vasin S. G., Gratsianskiy Ye. V. Osnovy protivodeistviya terrorizmu : ucheb. posobiye dlya stud. vyssh. ucheb. zavedenii [Bases of counteraction to terrorism: studies. allowance for students. higher. Studies'. Institutions ']; pod red. Vishnyakova Ya. D. Moscow, Izdatel'skii tsentr «Akademiya», 2006. 240 p.

5. Novoselov A. L., Medvedeva O. Ye., Novoselova I. Yu. Ekonomika, organizatsiya i upravlenie v oblasti nedropol'zovaniya [Economics, organization and management in the field of subsoil use. Textbook and practicum]. Uchebnik i praktikum. Moscow, 2017. $625 \mathrm{p}$.

6. Yakovlev A. Yu. Terrorizm v Indii: osobennosti evolyutsii, instituty i tekhnologii protivodeistviya: dis. d-r. polit. nauk: 23.00 .02 [Terrorism in India: features of evolution, institutions and technologies of counteraction: dis. . Dr. polit. Sciences: 23.00.02]. Moscow, 2016. 327 p.

7. Ofitsial'no Rossiya podtverdila, chto gotovitsya k voine s SSHA [Officially. Russia confirmed that it is preparing for war with the United States]. Available at: https://bb.lv/statja/v-mire/2018/10/27/oficialno-rossiya-podtverdila-chto-gotovitsya-k-voyne-s-ssha (accessed 10.01.2019). 